\title{
Evaluation of tumor heterogeneity of prostate carcinoma by flow- and image DNA cytometry and histopathological grading
}

\author{
Naining Wang a ${ }^{\text {, Claudia Wilkin }}{ }^{\mathrm{b}}$, \\ Alfred Böcking ${ }^{\mathrm{b}}$ and Bernhard Tribukait ${ }^{\mathrm{a}, *}$

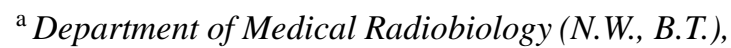 \\ Karolinska Institute, Stockholm, Sweden \\ ${ }^{\mathrm{b}}$ Institute of Cytopathology (C.W., A.B.), Heinrich \\ Heine University, Dusseldorf, Germany
}

Received 27 September 1999

Accepted 3 March 2000

Background. Heterogeneity of prostate carcinoma is one of the reasons for pretreatment underestimation of tumor aggressiveness. We studied tumor heterogeneity and the probability of finding the highest tumor grade and DNA aneuploidy with relation to the number of biopsies.

Material and methods. Specimens simulating core biopsies from five randomly selected tumor areas from each of 16 Böcking's grade II and 23 grade III prostate carcinomas were analyzed for tumor grade and DNA ploidy by flow- and fluorescence image cytometry (FCM, FICM). Cell cycle composition was measured by FCM.

Results. By determination of ploidy and cell cycle composition, morphologically defined tumors can further be subdivided. Heterogeneity of tumor grade and DNA ploidy (FCM) was $54 \%$ and $50 \%$. Coexistence of diploid tumor cells in aneuploid specimens represents another form of tumor heterogeneity. The proportion of diploid tumor cells decreased significantly with tumor grade and with increase in the fraction of proliferating cell of the aneuploid tumor part. The probability of estimating the highest tumor grade or aneuploidy increased from $40 \%$ for one biopsy to $95 \%$ for 5 biopsies studied. By combining the tumor grade with DNA ploidy, the probability of detecting a highly aggressive tumor increased from $40 \%$ to $70 \%$ and $90 \%$ for one and two biopsies, respectively.

Conclusion. Specimens of the size of core biopsies can be used for evaluation of DNA ploidy and cell cycle compo-

\footnotetext{
${ }^{*}$ Correspondence to Professor Bernhard Tribukait, M.D., Ph.D., Department of Medical Radiobiology, Karolinska Institute, 17176 Stockholm, Sweden. Tel.: +46 8 51774361; Fax: +46 851775042.
}

sition. Underestimation of aggressiveness of prostate carcinoma due to tumor heterogeneity is minimized by simultaneous study of the tumor grade and DNA ploidy more than by increasing the number of biopsies. The biological significance of coexistent diploid tumor cell in aneuploid lesions remains to be evaluated.

Keywords: Tumor heterogeneity, histopathological grade, DNA ploidy, S-phase, prostate cancer

\section{Introduction}

Ultrasound guided core biopsy as well as fine needle aspiration biopsy techniques have widespread use in the pretreatment diagnosis of prostate carcinoma. From comparative studies of core biopsies and the specimens from prostatectomy there is known to be a substantial risk of underestimating the tumor aggressiveness by core biopsies $[3,8,25,31]$. Tumor heterogeneity is one of the main reasons. In order to increase the accuracy of the clinical pretreatment evaluation, prostate "mapping" by systematic biopsies is frequently used both for the assessment of tumor extent and identification of high grade tumors $[11,21]$.

Tumor heterogeneity can be found in different foci of multifocal lesions or within the same tumor area. This has been demonstrated by studies of morphology, DNA ploidy and chromosomal alterations $[16,22$, $23,28,30,37,43]$. DNA ploidy in prostate carcinomas has been extensively studied and has been found to provided prognostic information independent of histologic grade and tumor stage $[27,36,44]$. Gross chromosomal aberrations as expressed by DNA aneuploidy correlates with poor survival of patients with prostate carcinoma $[1,4,7,10,12,27,29,36,44]$. In the present investigation we studied the heterogeneity of prostate carcinoma by histopathologic and DNA cytometric techniques.

Based on the results from the study of five randomly selected tumor areas and the overall tumor evaluation 
at the occasion of diagnosis, we calculated the probability of detecting the highest degree of tumor aggressiveness by the numbers of specimens and by combining the results of the morphological evaluation with the results of DNA cytometry.

\section{Material and methods}

Archival specimens from 39 adenocarcinomas of the prostate were included in this study. All tumors were T2 or T3 tumors according to the 1992 TNM system [32]. Cell material was obtained after radical prostatectomy ( $n=16$ ) and after transurethral resection of prostate $(n=23)$. The specimens were fixed in buffered formalin and embedded in paraffin. The mean storage time of the blocks was 34 months ( 3 to 76 months) before DNA determination. After determination of the tumor grade from the initial overall evaluation, the grade from five randomly selected tumor areas was evaluated separately. From these areas small pieces about of the size of punch biopsies and, thus, simulating these were excised for determination of DNA ploidy and cell cycle analysis. Specimens from the pooled rest of the tumor areas and from a nontumor area as a control were also analyzed. The median age of the patients was 71 years (range 55-83 years).

\subsection{Histological grading}

The tumor grade was evaluated according to the classification of Böcking et al. [6] by one of us (A.B.). This grading system combines the observations of histological growth pattern with nuclear anaplasia. Four growth patterns were distinguished: well differentiated, poorly differentiated, cribriform, and solid undifferentiated classified as 1, 2, 3 and 4. The nuclear anaplasia of the cells was classified as mild, moderately and marked indicated as 1,2 and 3. The two were combined into scores. Combined scores 2 and 3 correspond to grade I, 4 and 5 to grade II and 6 and 7 to grade III. The highest grade of the primary evaluation was used as the reference for the comparison with that from the selected tumor areas.

\subsection{DNA flow cytometry and fluorescence image cytometry}

\subsubsection{Preparation and staining of cell nuclei}

Preparation of the cell nuclei was carried out as described previously $[20,42]$. Briefly, each specimen was put into a bag of nylon mesh, deparaffinized, rehydrogenated and incubated for $1 / 2 \mathrm{hr}$ at $37^{\circ} \mathrm{C}$ in $1 \mathrm{ml}$ solution of Subtilisin Carlsberg (0.1\% Sigma protease XXIV, 0.1 M Tris buffer, 0.07 M NaCl, pH 7.2). Suspensions of cell nuclei were stained by directly adding $1 \mathrm{ml}$ of DAPI solution (10 $\mu \mathrm{M}$ DAPI in $800 \mathrm{mM}$ disodium-hydrogenphosphate). Before measuring the DNA content of the nuclei, the suspensions of cell nuclei were inspected microscopically in order to control adequate and good quality of the cell material. The majority of the suspension was used for DNA flow cytometry. A small part of the suspension was also dropped on slides for fluorescence measurement by image cytometry.

\subsubsection{Flow cytometry}

The cell nuclei were analyzed with a PAS II flow cytometer (Partec, Münster, Germany). For cell cycle analysis, the sliced nuclei option for background subtraction of the Multicycle program (Version 3.0, Phoenix Flow System, San Diego, CA, USA) was used. DNA histograms with a single peak were classified as diploid. Histograms with a distinct additional peak, containing at least $5 \%$ of the cell material with a corresponding $\mathrm{G} 2+\mathrm{M}$ peak, were classified as aneuploid [33]. A tetraploid histogram was assumed to be present when the proportion of tetraploid cells exceeded $6 \%$ which was the mean +3 standard deviations $(2.0 \%+3 \times 1.1 \%)$ of the $\mathrm{G} 2 / \mathrm{M}$ cells found in 37 controls. The range of tetraploidy was 3.8 to $4.2 \mathrm{c}$, which was 3 times beyond the standard deviation $(0.06 \mathrm{c}$ ) of the G2/G1 ratio found in the 37 controls. Non-tetraploid aneuploid histograms, thus, were considered for the DNA histograms with peaks outside the diploid and tetraploid ranges. The degree of DNA ploidy of the non-tetraploid aneuploid histograms was calculated in relation to the $2 \mathrm{c}$ peak. For estimation of the S-phase fraction in tumors with multiple aneuploid cell populations, the average S-phase value of the different aneuploid cell populations was calculated if these cell populations were present in an individual specimen. The coefficient of variation $(\mathrm{CV})$ was calculated from the Gaussian distributed shape of the G1 peaks.

\subsubsection{Fluorescence image cytometry}

The system for fluorescence image cytometry has been described previously [42]. Briefly, an epi-illumination fluorescence microscope was used, equipped with a $40 \times$ dry objective and a $100 \mathrm{~W}$ mercury arc lamp and the filter block for DAPI fluorescence measurement (excitation light filter with transmission be- 
tween $340 \mathrm{~nm}$ and $380 \mathrm{~nm}$, a beam-splitting mirror with the edge at $400 \mathrm{~nm}$, and a barrier filter with the edge at $430 \mathrm{~nm}$ ). The fluorescence intensity was measured with a single chip CCD camera (VI-470, Optronics Engineering, Goleta, CA, USA) in combination with the Ahrens Cytometry Analysis System (ACAS version 5.00, Bargteheide/Hamburg, Germany). Usually more than two hundred identified nuclei were randomly measured in each sample. As reference standard normal granulocytes, lymphocytes and fibroblasts were used.

A diploid DNA histogram was considered when a single peak was found in the DNA ploidy range $1.8 \mathrm{c}-2.2 \mathrm{c}$ according to the reference cells and when the proportion of tetraploid cells was less than $8 \%$ (mean $+3 \times \mathrm{SD}$ of the controls). The percentage of G2/M cells from 24 diploid non-tumor controls was $2.1 \pm 1.9 \%$ (mean $\pm \mathrm{SD}$ ). If the percentage of tetraploid cells (DNA ploidy 3.6-4.4c), which was in agreement with the recommendations of ESACP consensus for DNA image cytometry [18] exceeded $8 \%$ the DNA histogram was classified as tetraploid. In non-tetraploid aneuploid DNA histograms, the G1 peak of the nontetraploid aneuploid cell populations was related to the diploid reference cells. In order to reach conformity between FCM and FICM in the terminology of DNA ploidy, we used in this study "diploid" and "tetraploid" instead of "peridiploid" and "peritetraploid" as recommended for the terminology of absorption image cytometry [18].

\subsection{Statistical analyses}

Mean values \pm SD were calculated and used in the text. For evaluation of differences, non-parametric Mann-Whitney and Chi-square tests were used. A $p$ value less than 0.05 was considered statistically significant. Based on the probability theorem [5], the probability of correct estimation of tumor grade by the number of randomly selected specimens was estimated from the percentage of the agreement between the results of the primary evaluation and those from the five specimens. For assessment of the probability of correct detection of tetraploid and non-tetraploid aneuploid tumors, the results from the randomly selected specimens were compared with those from the pooled remaining tumor material. For the calculation of the probability of the tumor aggressiveness based on histopathologic grade and DNA ploidy together, the tumor grade and DNA ploidy were assumed to be mutually independent events. The reciprocal regression analysis was used for the percentage of DNA diploid tumor cells in non-diploid specimens in relation to the percentage of $\mathrm{S}+\mathrm{G} 2 / \mathrm{M}$ cells of the non-diploid tumor. The logarithmic fit was applied for the regression evaluation of the probabilities of observed results by increase number of specimens.

The chance to find a tumor-characterizing feature (poorest histological grade or non-tetraploid aneuploidy, etc.) in a heterogeneous tumor can theoretically be described by binomial distributions:

If

$$
p_{n, m}=\left(\begin{array}{c}
n \\
m
\end{array}\right) p^{m}(1-p)^{n-m}
$$

with

$p$, probability of occurrence for an event (poorest grade) in one test,

$n$, number of test, $m$, number of "events"

then

$$
\sum_{i=1}^{n} p_{n, m}=1-p_{n, 0}
$$

and according to (1) and (2) with

$$
\begin{aligned}
& \left(\begin{array}{l}
n \\
0
\end{array}\right)=1 \text { and }\left(\begin{array}{l}
p \\
0
\end{array}\right)=1 \\
& =1-1 \times 1 \times(1-p)^{n} .
\end{aligned}
$$

It is evident that one can calculate the probability of occurrence of such a feature in $n$ test (samples), if the probability of occurrence $p$ in one sample is known. To analysis the relationship between observed results and theoretically calculated ones, the linear regression evaluation was used.

\section{Results}

\subsection{Heterogeneity of tumor grade}

Five tumor specimens together with non-tumor control areas from each of 39 prostate carcinomas were histopathologically reevaluated. There were 16 tumors of grade II, and 23 of grade III according to the primary evaluation. 


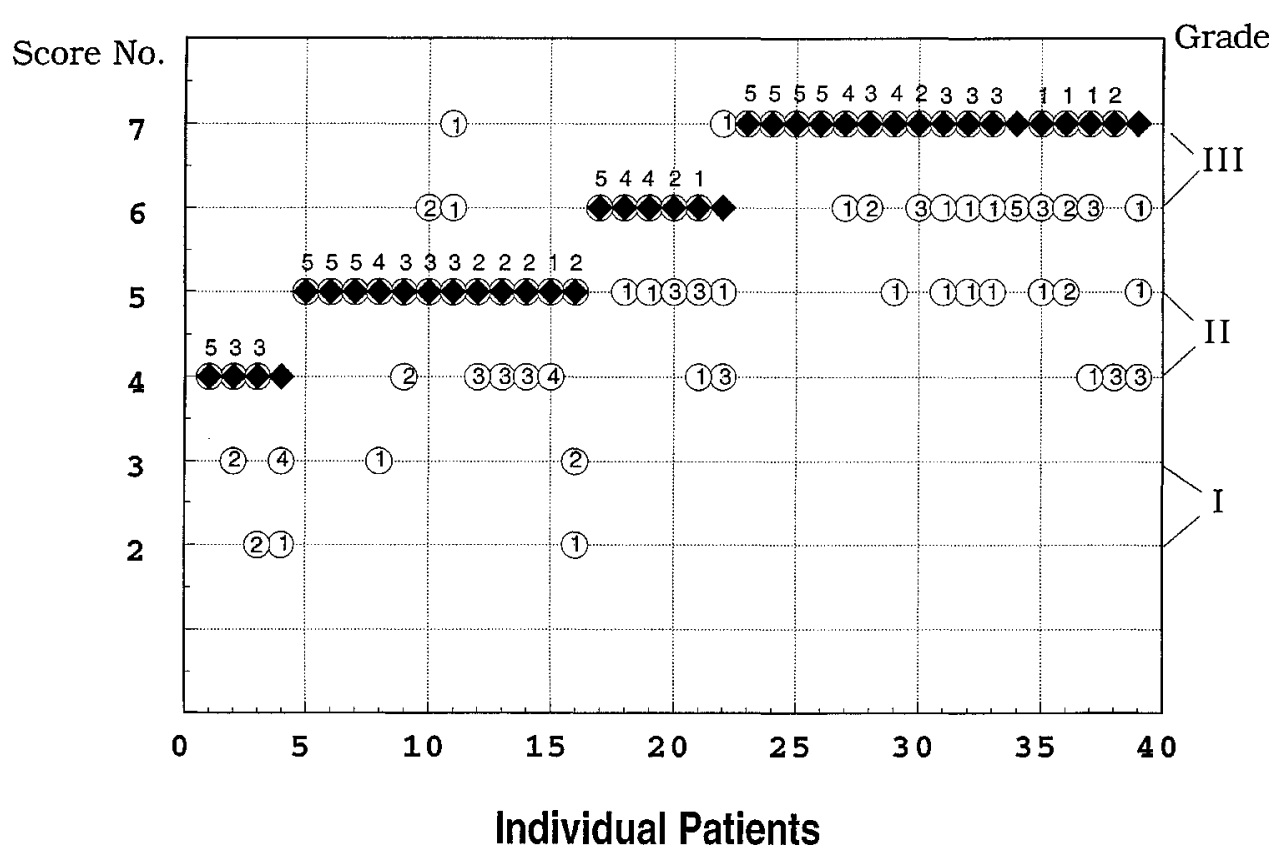

Fig. 1. Histopathological evaluation of five randomly selected tumor parts (circles) from 39 patients with prostate carcinoma. Numbers indicate specimens with the same score values. Filled diamonds indicate results from the primary overall evaluation. Score $2+3=$ Grade $\mathrm{I} ; 4+5=$ Grade II and $6+7=$ Grade III.

An overview of the individual scores and tumor grades of the randomly selected tumor areas together with the highest score and grade at the primary evaluation is shown in Fig. 1. In order to quantify the degree of heterogeneity of the tumor grade the differences between the scores found in the five randomly selected specimens and the highest score of the primary evaluation were summed up. For example, the score of the primary evaluation was 5 in patient No. 16 . Two specimens from this tumor had a score of $3(2 \times 2$ different degrees), one a score of 2 ( 3 different degrees) and two a score of 5 (no different). Thus, the degree of heterogeneity of the tumor grade was 7 .

The mean degree of heterogeneity was 2.3 (range 0 6 ) in the four tumors with score 4, 2.4 (range 0 to 7) in the 12 tumors with score $5,3.0$ (range 0 to 8 ) in six tumors with score 6 , and 3.5 (range $0-12$ ) in the 16 tumors with score 7. The degree of histopathological tumor heterogeneity was independent of the tumor score ( $p=0.91)$. Considering tumor grade from the combined scores, $44 \%$ of the 16 grade II tumors and $61 \%$ of the 23 grade III tumors revealed heterogeneity (Chisquare, $p=0.29$ ). In total, $54 \%$ of the 39 prostate carcinomas displayed morphological tumor heterogeneity according to the evaluation of the three-category tumor grade.

\subsection{Heterogeneity of DNA ploidy}

\subsubsection{Non-tumor controls}

Thirty-seven of 39 non-malignant control areas according to histopathology were found to be diploid by both FCM and FICM. In one morphologically benign specimen a non-tetraploid aneuploid DNA pattern was found by both methods, in another one $70 \%$ of the cells were DNA tetraploid according to FICM.

\subsubsection{Determination of DNA ploidy by FCM}

Histograms from 229 of 234 tumor specimens (98\%) could be evaluated. The mean CV of these specimens was $4.6 \pm 1.2$. Five specimens from one tumor with CVs $>8.0 \%$ were excluded. According to the results of 38 tumors in which pooled tumor material was available, 11 of 38 (29\%) tumors were DNA-diploid, 13 (34\%) tetraploid, and 14 (37\%) nontetraploid aneuploid. Six of the non-tetraploid aneuploid tumors were multiple aneuploid (multiple nontetraploid or tetraploid and non-tetraploid aneuploid). Figure 2 shows the heterogeneity of DNA ploidy in the various specimens of each tumor. Eleven tumors were diploid in all specimens. Diploid specimens were found in 6 out of 11 tetraploid tumors. Among the 17 tumors with at least one non-tetraploid aneuploid specimen, three had the same ploidy value in all 5 spec- 


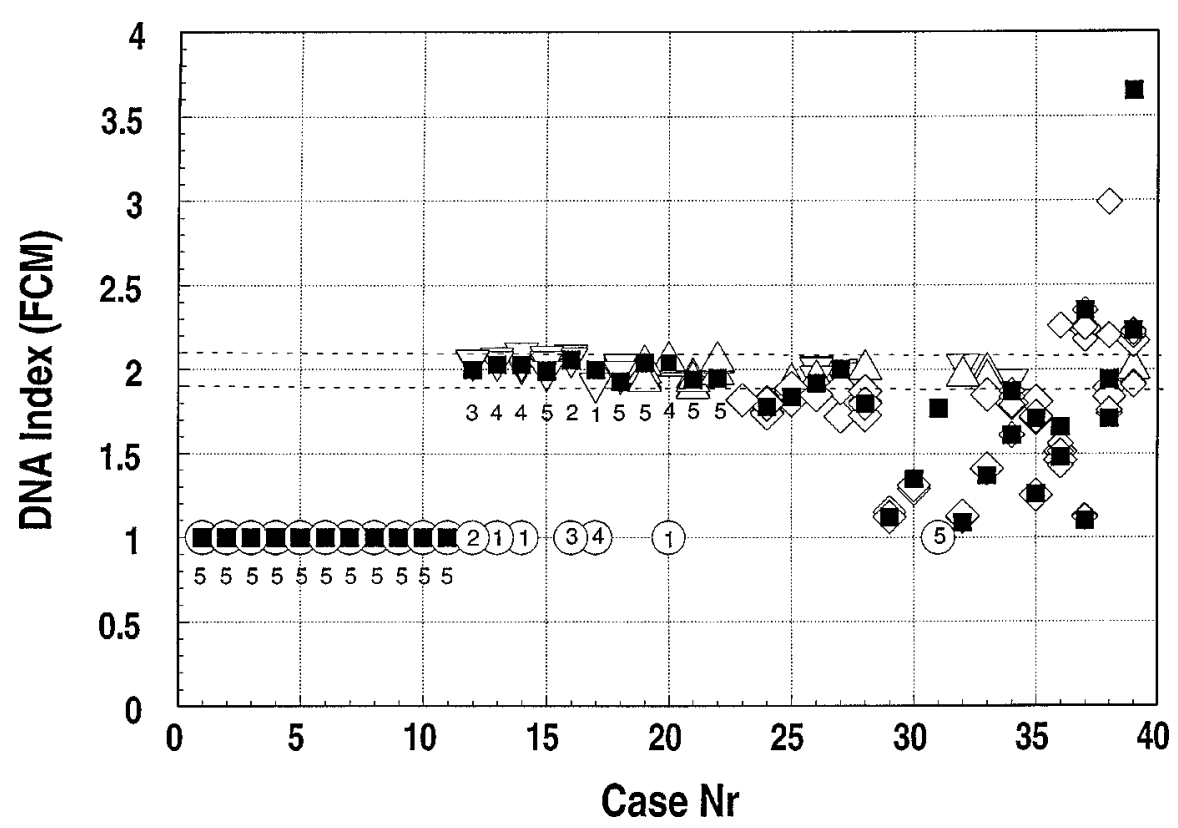

Fig. 2. DNA ploidy of five randomly selected tumor parts from 39 patients with prostate carcinoma as measured by DNA-flow cytometry. Numbers indicate specimens with the same ploidy values. Diploid $(\bigcirc)$, tetraploid without octoploid cells $(\nabla)$, tetraploid with octoploid cells $(\triangle)$, non-tetraploid aneuploid $(\diamond)$, pooled cell material $(\boldsymbol{\square})$. Dot lines indicate the tetraploid range.

imens, 6 had additional tetraploid specimens and 6 had different aneuploid cell populations. In one case, the pooled cell material was non-tetraploid aneuploid but all 5 randomly selected specimens were diploid. In another tumor, only one sample was available which was non-tetraploid aneuploid. The pooled cell material from the tumors corresponded to at least one cell population of the randomly selected specimens except in the one case already mentioned. Totally, 143 of the 229 specimens contained non-diploid cell populations. Mean proportion of non-diploid cells per specimen was $53.8 \%$ (range $9.1-98.1 \%$ ). Heterogeneity of DNA ploidy was found in 19 of $38(50 \%)$ tumors.

\subsection{Cell cycle analysis by FCM}

The cell cycle composition could be evaluated in 31 of 39 DNA diploid controls and 187 of 229 tumor specimens, depending on the quality of the DNA histograms. The S-phase and G2/M fraction of the control specimens was $2.1 \pm 1.1 \%$ and $2.0 \pm 1.1 \%$, respectively. Figure 3 shows the variation of S-phase values in the different tumor specimens. Obviously, the intratumor variation of S-phase fractions was less than the intertumor variation. The S-phase fraction from the pooled tumor material deviated in only a few cases from the randomly selected specimens. Most of the tetraploid tumor specimens had S-phase values as low as diploid tumor ones, and the means, $3.2 \pm 2.5 \%$ and $2.7 \pm 2.0 \%$, respectively, did not differ from each other $(p=0.21)$. The mean S-phase fraction of nontetraploid aneuploid specimens $5.5 \pm 2.4 \%$ was significantly higher than those from the diploid and tetraploid specimens ( $p<0.001$ and $p<0.001$, respectively). Seven out of 11 tetraploid tumors contained almost no octoploid G2/M cells, and these tumors had generally very low $\mathrm{S}$-phase values. Thus, these tumors could also be classified as diploid with G2/M arrest. It can be also noted that diploid tumors may have S-phase values as high as non-tetraploid aneuploid tumors, but also nontetraploid aneuploid tumor may have low S-phase values not different from the diploid ones. All together, 13 tumors had S-phase values exceeding 6\% (mean + 3 SD of non-tumor controls) considered to be high, and 11 of them were of grade III or non-tetraploid aneuploid.

\subsection{DNA ploidy and cell cycle composition in relation to tumor grade}

DNA ploidy as measured by FCM is related to the results of histopathology in Fig. 4. The proportion of diploid lesions decreased significantly from $100 \%$ in grade I (score 2 or 3 ) lesions, to $74 \%$ and $43 \%$ in grade 


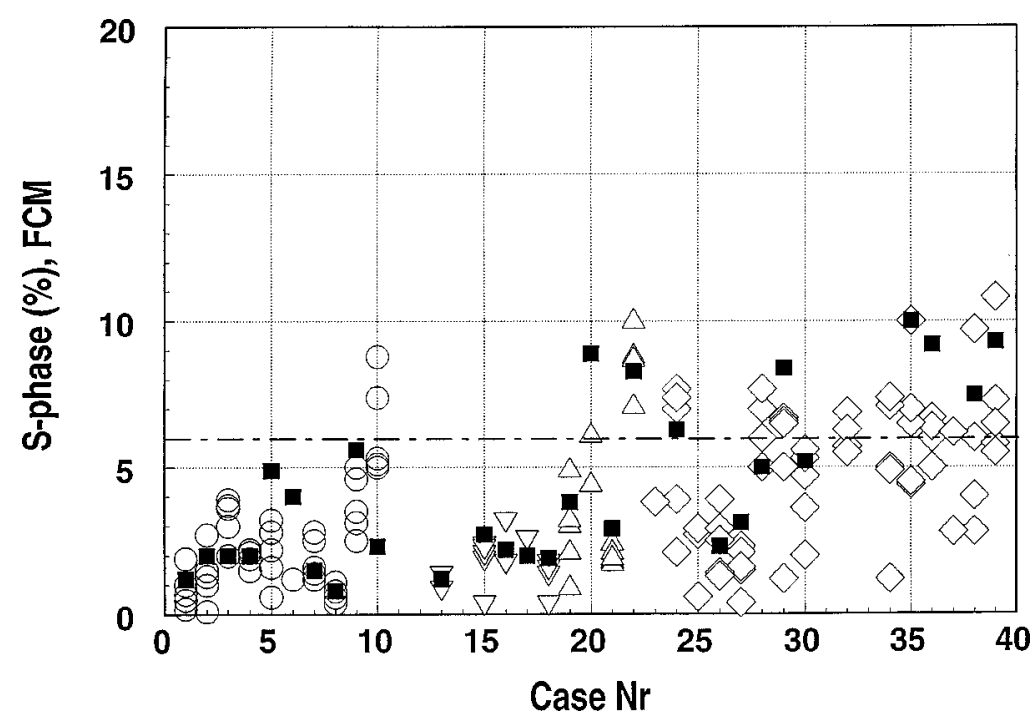

Fig. 3. S-phase fraction of five randomly selected tumor parts from 31 patients with prostate carcinoma. Diploid $(\bigcirc)$, tetraploid without octoploid cells $(\nabla)$, tetraploid with octoploid cells $(\triangle)$, non-tetraploid aneuploid $(\diamond)$, pooled cell material (

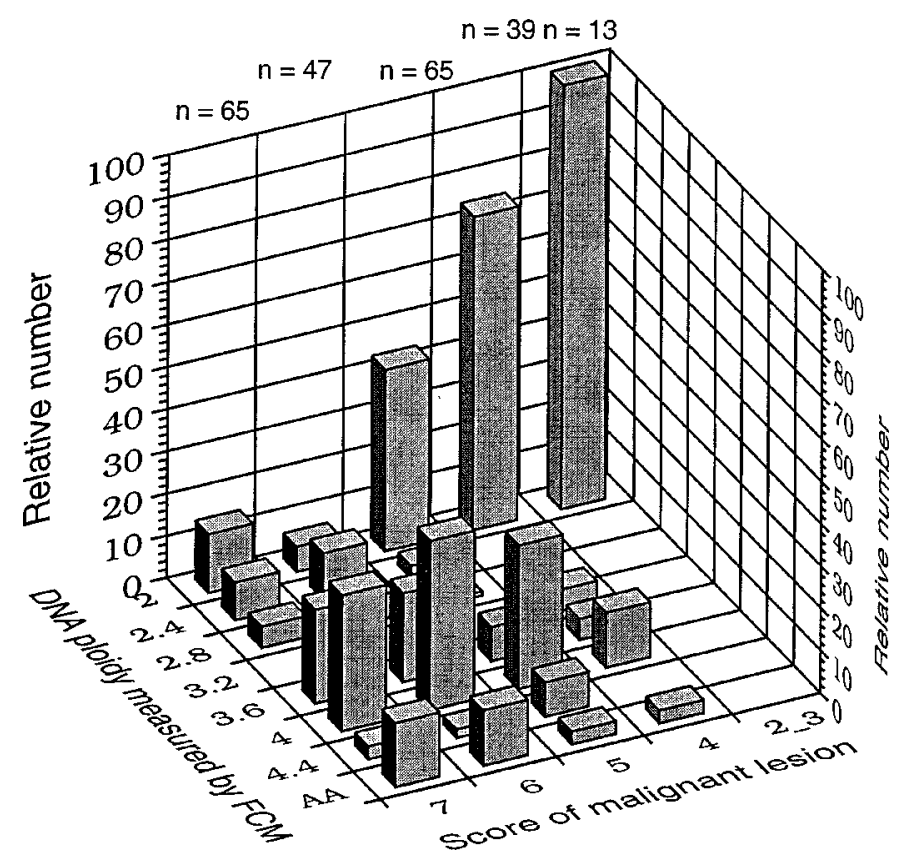

Fig. 4. Relationship between DNA-ploidy and histopathological score of malignancy in 229 specimens from 39 prostate carcinomas.

II (score 4 or 5) lesions, and $6 \%$ and $14 \%$ in grade III (score 6 or 7) lesions (Chi-square test, $p<0.0001$ ). The change from the diploid to non-diploid lesions in grade II was mainly due to an increase of tetraploid lesions in score 5 specimens. Regarding the distribution of ploidy in grade III lesions, there was no difference between score 6 and 7 and various non-diploid specimens.
No difference of the fractions of S-phase and G2/M was found between grade I and grade II specimens, the means of which were $2.3 \pm 1.3 \%$ and $1.7 \pm 1.1 \%$ for grade I, and $2.8 \pm 2.1 \%$ and $2.3 \pm 1.9 \%$ for grade II, respectively ( $p=0.88$ and $p=0.45$ ). The fractions of S-phase and G2/M of grade III tumor sample were $4.8 \pm 2.7 \%$ and $3.4 \pm 2.8 \%$, they were significantly higher than those of grade I and II specimens 
Table 1

Histogical grade as related to DNA ploidy, S-phase- and G2 fraction in 225 specimens from 39 prostate carcinomas $(n=$ number)

\begin{tabular}{|c|c|c|c|c|c|c|c|c|c|}
\hline \multirow{2}{*}{$\begin{array}{l}\text { Benign and } \\
\text { tumor grade }\end{array}$} & \multicolumn{3}{|c|}{ Diploid } & \multicolumn{3}{|c|}{ Tetraploid } & \multicolumn{3}{|c|}{ Aneuploid } \\
\hline & $n$ & S-phase, $\%$ & $\mathrm{G} 2, \%$ & $n$ & S-phase, $\%$ & $\mathrm{G} 2, \%$ & $n$ & S-phase, \% & $\mathrm{G} 2, \%$ \\
\hline Benign & 31 & $2.1 \pm 1.1$ & $2.0 \pm 1.1$ & & & & & & \\
\hline \multicolumn{10}{|l|}{ Grade } \\
\hline $\mathrm{I}$ & 13 & $2.3 \pm 1.3$ & $1.7 \pm 1.1$ & & & & & & \\
\hline II & 58 & $2.5 \pm 1.9$ & $2.6 \pm 1.4$ & 19 & $2.4 \pm 1.9$ & $0.9 \pm 1.6$ & 13 & $4.8 \pm 2.1$ & $3.7 \pm 2.6$ \\
\hline III & 12 & $4.8 \pm 2.3$ & $4.2 \pm 1.9$ & 32 & $3.5 \pm 2.7$ & $2.3 \pm 2.1$ & 47 & $5.7 \pm 2.4$ & $4.0 \pm 3.1$ \\
\hline
\end{tabular}

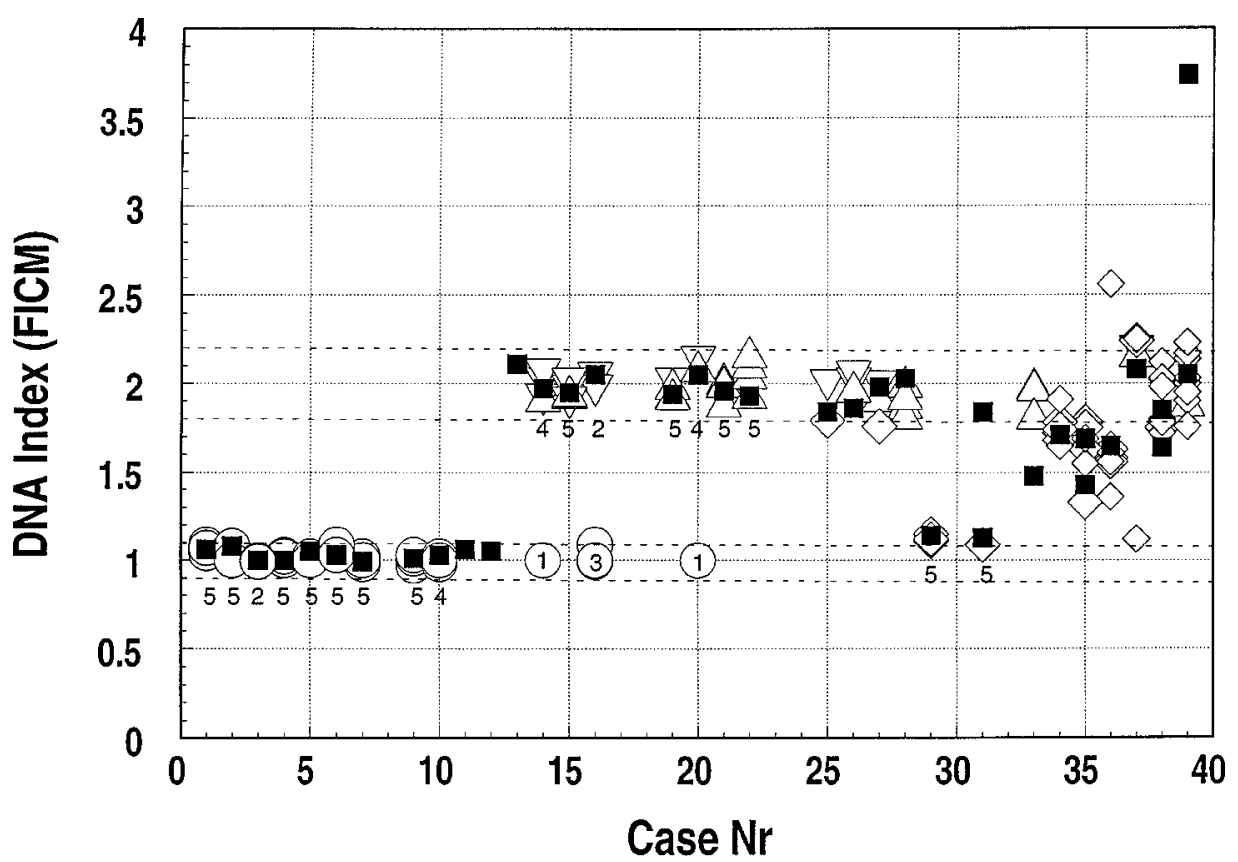

Fig. 5. DNA ploidy of five randomly selected tumor parts from 31 patients with prostate carcinoma as measured by DNA-fluorescence image cytometry. Numbers indicate specimens with the same score values. Diploid $(\bigcirc)$, tetraploid without octoploid cells $(\nabla)$, tetraploid with octoploid cells $(\triangle)$, non-tetraploid aneuploid $(\diamond)$, pooled cell material $(\boldsymbol{\square})$, tumor specimens. Dot lines indicate the diploid and tetraploid ranges.

$(p<0.0001$ and $p=0.002)$. The mean S-phase fraction of non-tetraploid aneuploid specimens $5.5 \pm 2.4 \%$ was significantly higher than those from the diploid and tetraploid specimens ( $p<0.001$ and $p<0.001$ ). The relationship between tumor grade and $S$-phase and $\mathrm{G} 2 / \mathrm{M}$ fraction of diploid and non-diploid specimens is also shown in Table 1. The increase of the S-phaseand $\mathrm{G} 2 / \mathrm{M}$ fraction in diploid lesions was significantly related to tumor grade ( $p=0.003$ and $p=0.0005$ ). In tetraploid specimens only the $\mathrm{G} 2 / \mathrm{M}$ fraction but not the S-phase fraction increased significantly ( $p=$ $0.0008)$. There was neither a difference of S-phase or G2/M fraction between non-tetraploid aneuploid grade II and grade III lesions ( $p=0.39$ and $p=0.44$ ), nor between diploid and non-diploid grade III lesions.

\subsection{Determination of DNA ploidy by FICM}

There were 165 of 234 tumor specimens (31 of 39 tumors) available for DNA-FICM analysis. The results shown in Fig. 5 are almost the same as those shown in Fig. 2 from FCM measurements. Due to a broader range for tetraploidy, the number of tetraploid specimens was higher than that found by FCM. Thirteen of the $31(42 \%)$ tumors revealed DNA heterogeneity by FICM.

\subsection{Determination of DNA diploid tumor cells in aneuploid tumors}

One of the advantages of the measurement by image cytometry over DNA flow cytometry, is the pos- 
sibility to identify and to quantify diploid tumor cells. Diploid tumor cells in tetraploid or non-tetraploid aneuploid tumors disclosed a further type of tumor heterogeneity not yet discussed. Figure 6 shows as an example various proportions of diploid tumor cells in the 6 specimens of a tetraploid tumor. There is a relationship between the amount of diploid cells as measured by FCM, and diploid tumor cells as identified by FICM, however, the proportion of diploid tumor cells can not be quantified by one-parametric DNA FCM. A median value of $14 \%$ diploid tumor cells was found by FICM in 97 tetraploid or non-tetraploid aneuploid specimens ranging between 0 and $79 \%$ (Table 2). The proportion of diploid tumor cells was found significantly higher in tetraploid tumors than in non-tetraploid ones $(p=$ $0.05)$ and higher in grade II tumors than in grade III ones $(p=0.04)$.

If we assume that the proliferation rate of the aneuploid tumor part of a tumor is higher than that of the diploid tumor part, a decrease in the proportion of diploid tumor cells with increase of proliferation of the aneuploid tumor part can be expected. Such an assumption is supported by data shown in Fig. 7, in which the increase in the proportion of $\mathrm{S}+\mathrm{G} 2 / \mathrm{M}$ cells as measured by FCM in tetraploid and non-tetraploid aneuploid tumors is significantly related to the decrease in the proportion of diploid tumor cells. Similar results were found when only S-phase values were measured or $\mathrm{S}+\mathrm{G} 2 / \mathrm{M}$ fractions were measured by FICM.

\subsection{Probability of detecting the highest degree of malignancy by number of specimens}

The degree of correct determination of the tumor grade was calculated from the agreement between the results of the five randomly selected specimens and the result of the overall primary evaluation. The probability increased from about $45 \%$ when only one specimen was studied up to $97 \%$ when all five specimens were evaluated (Fig. 8). There was no difference between grade II and grade III tumors.

Corresponding calculations were performed for DNA ploidy to detect tetraploid or non-tetraploid aneuploid cell populations in one of the specimens relative to the pooled remaining tumor material (Fig. 9). The probability to find a DNA tetraploid or non-tetraploid aneuploid tumor increased from about $40 \%$ by one specimen up to $100 \%$ and $94 \%$, respectively, by 5 specimens. There was no difference between tetraploid and non-tetraploid aneuploid tumors.
Grade III and DNA non-tetraploid aneuploidy are known to be signs of high tumor aggressiveness and poor prognosis. Therefore, the results from the histopathological evaluation and the measurement of DNA ploidy were combined and the probability to detect a highly aggressive tumor (grade III and/or non-DNA tetraploid aneuploidy) by one of the both methods was studied (Fig. 10). By combining tumor grade with DNA ploidy, the probability to detect a highly aggressive tumor increased from about $40 \%$ to about $70 \%$ already when one specimen was studied and to about 90\% for two specimens studied.

The probability of correct determination of tumor grade, DNA-tetraploidy or non-tetraploid DNAaneuploidy by increasing the number of specimens could be calculated according to the model of binomial distribution. The observed probability did almost perfectly fit the calculated results for the grade II ( $p=$ $\left.0.03, r^{2}=0.82\right)$, grade III $\left(p=0.003, r^{2}=0.97\right)$, tetraploid ( $p=0.02, r^{2}=0.88$ ) and non-tetraploid aneuploid ( $p=0.009, r^{2}=0.92$ ) tumors, respectively. The observed results in relation to the calculated ones for the grade III and/or the non-tetraploid aneuploid tumors did almost reach significance $\left(p=0.07, r^{2}=\right.$ $0.73)$.

\section{Discussion}

Prostate carcinoma is known to harbor variable histological and cytological patterns within one and the same tumor area or different parts of a multifocal tumor. The heterogeneity of the architectural glandular pattern has been combined by Gleason in his scoring sum system $[14,15]$. Gleason found two or more architectural patterns in more than half of the cancers studied [15]. The Böcking grading system used in this study combines histological growth patterns with nuclear anaplasia, and the highest grade is routinely recorded to define the degree of malignancy of a tumor [6]. Morphological tumor heterogeneity was found in $54 \%$ of the 39 carcinomas studied in our investigation, based on the evaluation of the five randomly selected areas from earlier identified tumor parts.

Heterogeneity of DNA ploidy has been described by various authors $[16,22,23,28,37,43]$. Depending on the number of samples studied, and the criteria used to define DNA ploidy categories (diploid, non-diploid; diploid, tetraploid, non-tetraploid aneuploid), heterogeneity of the DNA patterns varied between about $4 \%$ 

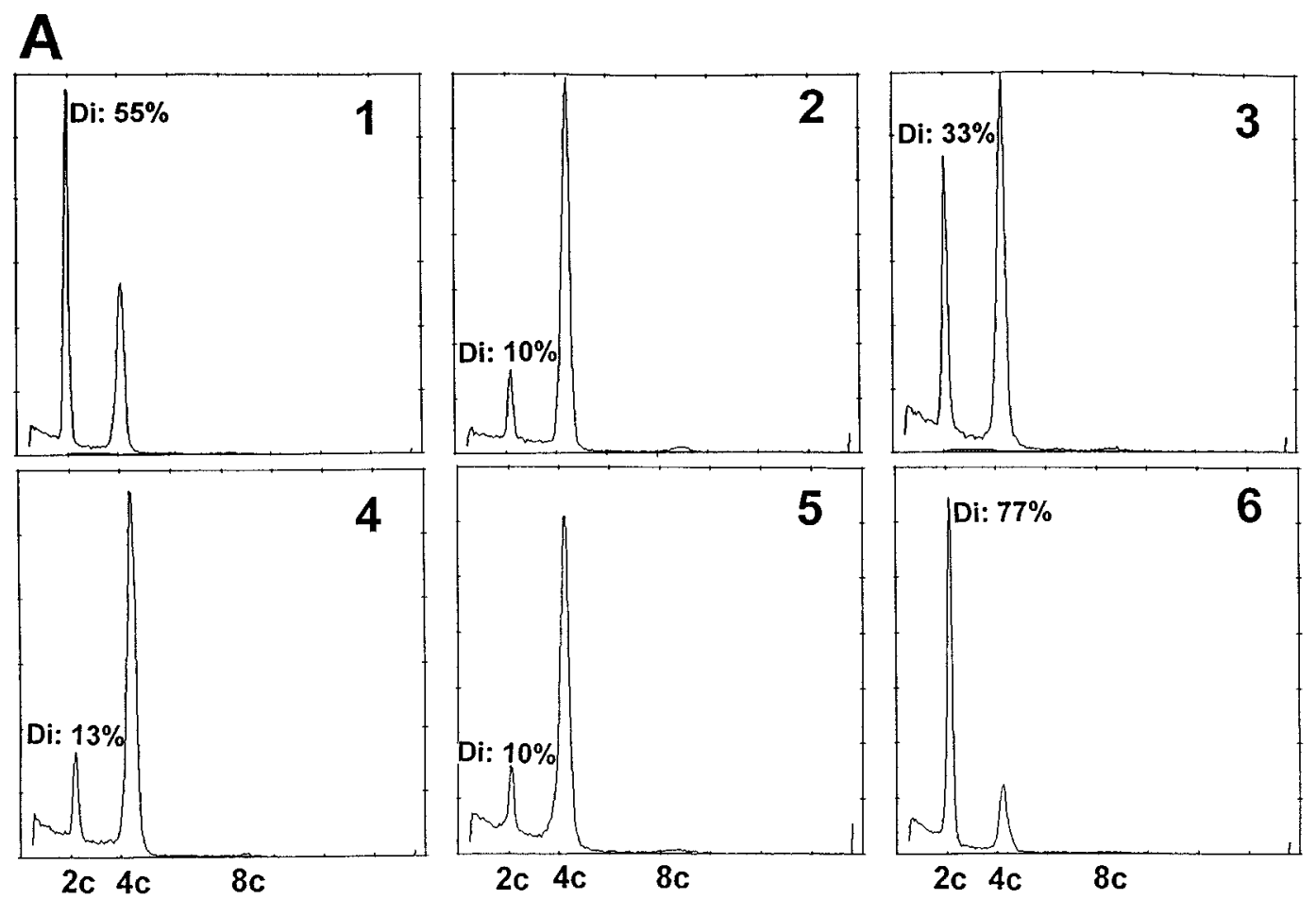

B

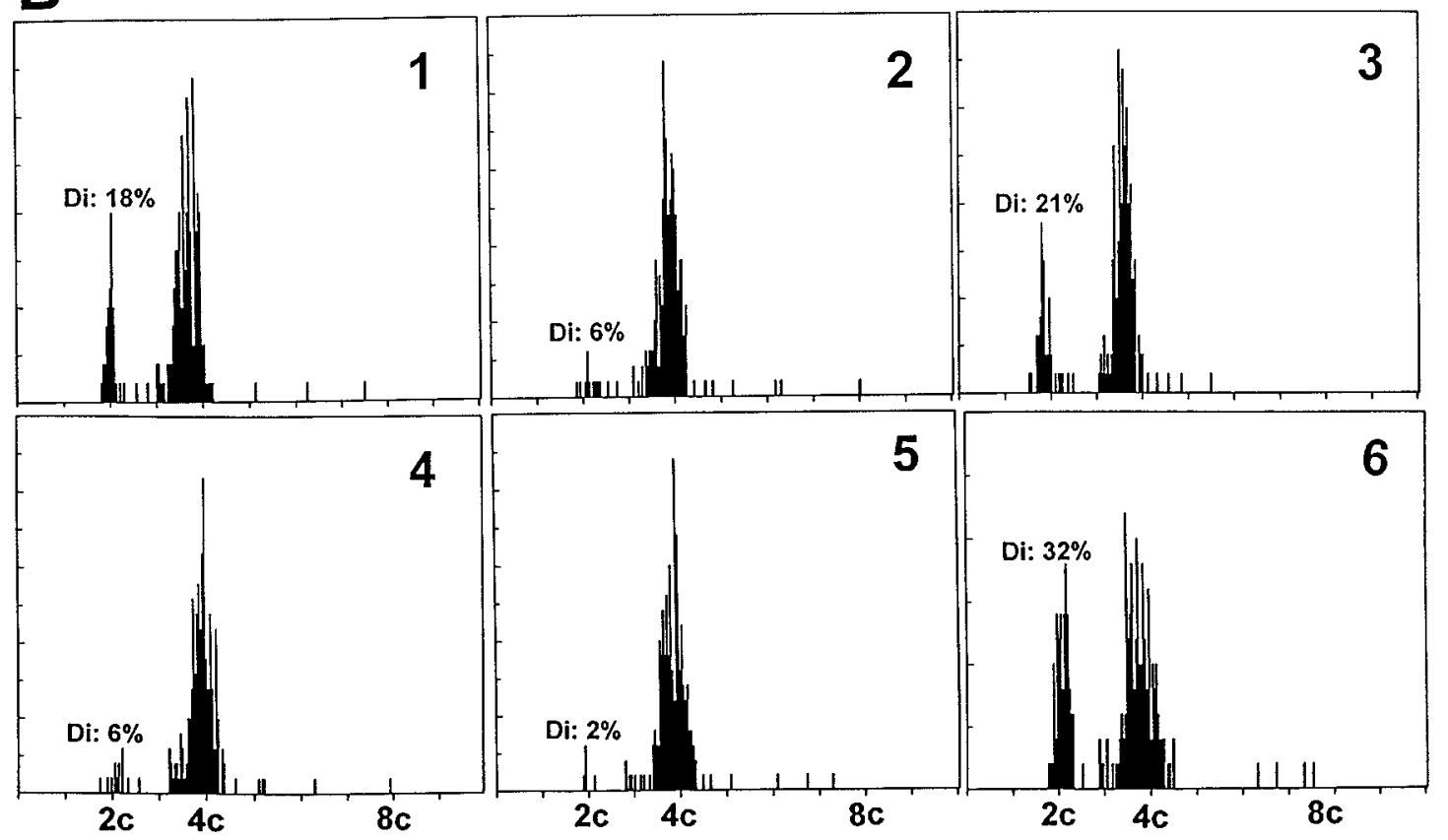

Fig. 6. DNA histograms of a tetraploid tumor as measured by FCM (A) and fluorescence image cytometry (B). The diploid parts of the DNA histograms measured by flow cytometry contain both tumor and normal cells, while those measured by fluorescence image cytometry contain only tumor cells. 1: pooled remaining cell material; 2-6: randomly selected specimens. 
Table 2

Proportion of diploid tumor cells in relation to DNA ploidy and histopathologic grade ( $n=$ number)

\begin{tabular}{|c|c|c|c|c|c|c|}
\hline \multirow{2}{*}{$\begin{array}{l}\text { Tumor grade/ } \\
\text { DNA ploidy }\end{array}$} & \multicolumn{2}{|r|}{ Grade II } & \multicolumn{2}{|r|}{ Grade III } & \multicolumn{2}{|r|}{ Total } \\
\hline & $n$ & Median (rang) & $n$ & Median (rang) & $n$ & Median (rang) \\
\hline Tetraploid & 20 & $21.7(1.0-79)$ & 46 & $12.0(0.5-77)$ & 66 & $16.2(0.5-79)$ \\
\hline Aneuploid & 7 & $6.5(0.5-34)$ & 24 & $11.7(0-49)$ & 31 & $10.0(0-49)$ \\
\hline Total & 27 & $21.0(0.5-79)$ & 70 & $12.0(0-77)$ & 97 & $13.6(0-79)$ \\
\hline
\end{tabular}

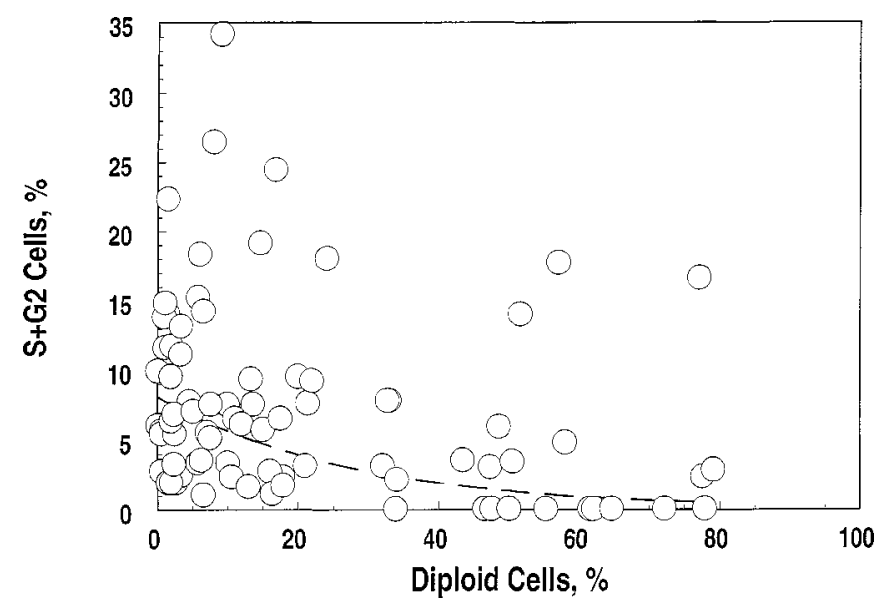

Fig. 7. Percentage of DNA diploid tumor cells in tetraploid and non-tetraploid aneuploid specimens in relation to the percentage of S + G2/M cells of the non-diploid tumor samples. Best fit by a reciprocal regression line is shown $\left(Y=8.13 \mathrm{e}^{-0.036 X}, r=0.57, p<0.001\right)$.

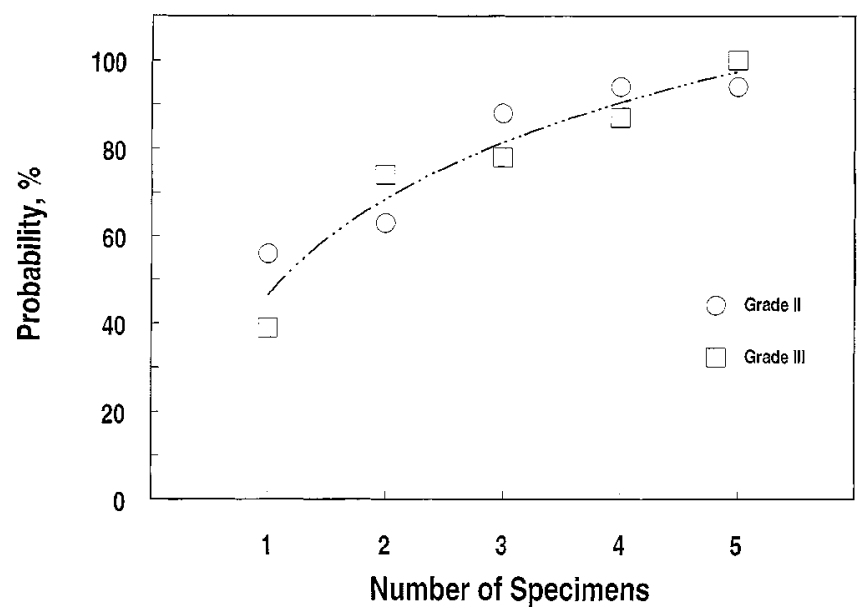

Fig. 8. Probability of correct estimation of tumor grade when five random specimens from 39 tumors were studied. The overall primary evaluation was taken as standard $(=100 \%)$.

and $40 \%[16,22,23,28,37,43]$. We discriminated between diploid, tetraploid and non-tetraploid aneuploid and found a heterogeneity of $50 \%$ for five specimens studied from each tumor. The size of the specimens was similar to that of core biopsies, but there was no difficulty in analyzing these small specimens although the low cell number in some cases ham- pered estimation of the S-phase fraction. When DNAFICM was used with a resolution of measurement not equally good as in DNA-FCM, heterogeneity was found in $42 \%$.

In the pretreatment evaluation of prostate carcinomas, tumor heterogeneity is a clear challenge and probably the major reason for undergrading needle biopsy 


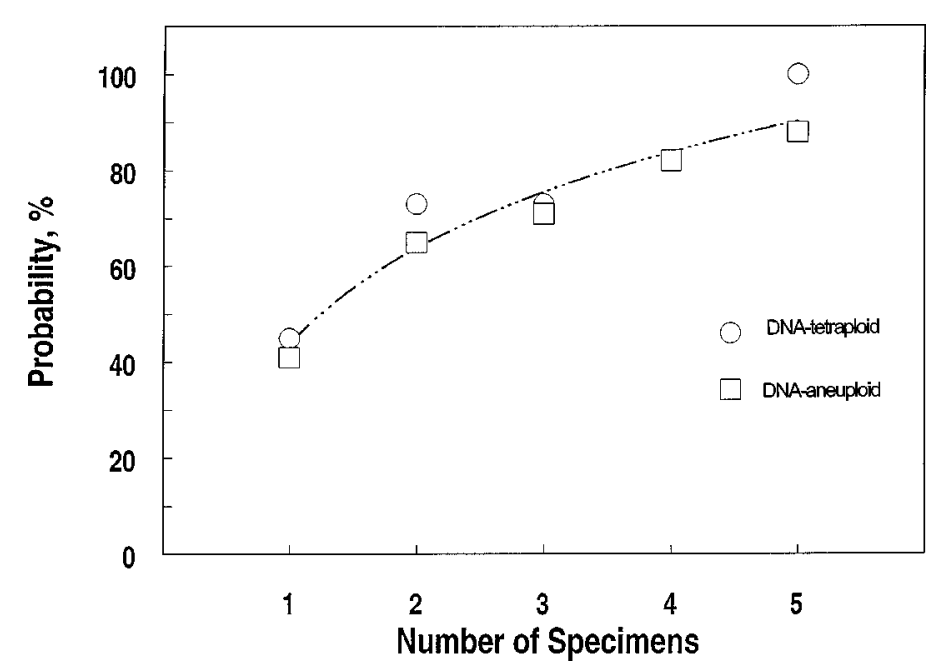

Fig. 9. Probability of correct estimation of DNA tetraploidy and non-tetraploid aneuploidy when five random specimens were studied. The results of the pooled cell material from 11 tetraploid and 17 non-tetraploid aneuploid tumors were used as standard $(=100 \%)$.

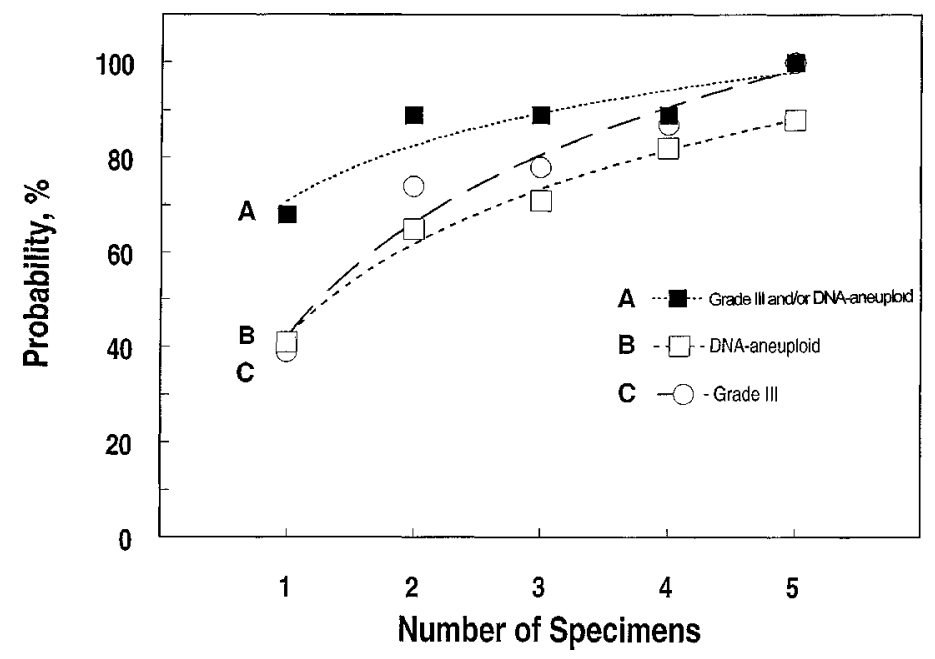

Fig. 10. Probability of correct estimation of highly aggressive tumors (Grade III and non-tetraploid aneuploidy, respectively). One to five random specimens from 19 Grade III and/or non-tetraploid aneuploid tumors were studied. A shows the results from simultaneous measurement by both methods. B and $\mathrm{C}$ show the results when tumor grade and ploidy were studied separately.

specimens [8]. Undergrading by needle biopsy specimens has been reported in $40 \%$ in large series of matched prostatectomy specimens, and in a higher frequency in low grade than in high grade tumors and inversely related to the tumor burden $[8,9,13]$.

In our study in which five randomly selected tumor specimens were compared with the overall primary histopathlogical evaluation, the probability of detecting the highest grade by one biopsy was not better than about 50\% irrespective the highest tumor grade was of grade II or III. The probability of detecting DNA tetraploid or non-tetraploid aneuploid cell pop- ulations in one of 5 biopsies was neither more than $50 \%$. The same frequencies of tumor heterogeneity found by both methods support the validity of the results.

By increasing the number of biopsies, the pretreatment accuracy increased. But still for three biopsies the probability of detecting the highest tumor grade or non-diploid DNA ploidy was no more than $80 \%$. By far more effective to detect highly aggressive tumors is to combine different methods in a prognostic index. Here we combined DNA aneuploidy as a high risk factor with grade III as the other well known high risk 
factor which resulted in an increase of the predictive value of each of the methods from about $40 \%$ to $70 \%$ when one specimen was studied by both methods. In this context we assumed independency of tumor grade and DNA-ploidy. This, however, may not be true which is also indicated by our data, since the observed probability of the correct detection of a grade III and/or a non-tetraploid aneuploid tumor by increasing the number of specimens was not as high as the theoretically calculated probability. Other parameters discussed to be included in a multiple prognostic pretreatment index are, in addition to tumor grade, serum PSA level, the estimation of the tumor extension by multiple core biopsies, the volume of the ultrasonographic hypoechoic lesion and gland volume [17,26].

Based on DNA ploidy measurements, morphologically defined tumor could further be subdivided. This was particularly true for the group of moderately differentiated tumors with diploid, tetraploid and nontetraploid aneuploid DNA ploidy variants.

In our flow cytometric study we included the analysis of the cell cycle composition. The prognostic significance of the size of S-phase fraction as measured by FCM in prostate tissue has been described by several authors $[29,34,39,41]$. The generally low values of the $\mathrm{S}$-phase fraction, but still significantly higher values in aneuploid than diploid prostate carcinomas found in this study, were in good agreement with our earlier experience [29]. Both DNA diploid and non-diploid tumors can be further subdivided according to the size of their S-phase fractions. Notably, high S-phase fractions were seen in grade III diploid lesions, not different from those of tetraploid and non-tetraploid aneuploid lesions. The fraction of S-phase cells, other markers of cell proliferation such as the Ki67 labeling index, or factors involved in the regulation of cell proliferation such as the expression of the $p 53$ gene or cyclins may in future be included into tests of a multiple prognostic pretreatment index [2,7,19,24,38,40].

In addition to the tumor heterogeneity discussed here and characterized by differences in the morphological appearance or DNA ploidy patterns of the various specimens, the coexistence of diploid tumor cells in tetraploid or non-tetraploid aneuploid tumors is another form of tumor heterogeneity hitherto generally not recognized or discussed in this context. The proportions of diploid tumor cells, $21 \%$ and $12 \%$ in grade II and grade III tumors, respectively, were about the same as found previously in another study of prostate carcinoma [42]. A new observation is the decrease in the proportion of diploid tumor cells with increase in the percentage of S-phase and G2/M cells of the aneuploid part of the tumor. Non-diploid grade III tumors have usually a higher proportion of S-phase cells than non-diploid grade II tumors. Therefore, a lower fraction of diploid tumor cells in grade III compared with that in grade II tumors further supports the significance of proliferation for the size of the diploid tumor part.

DNA diploid tumor cells in aneuploid tumors are expected when it is assumed that the development of prostate carcinoma starts with an initially neardiploid tumor, which is subsequently transformed into a tetraploid tumor and finally, by loss or gain of chromosomes, into a non-tetraploid aneuploid tumor. A compartment model for development of prostate carcinoma has been earlier suggested on the basis of DNA-ploidy measurements in a large number of patients with newly detected prostate carcinomas of different stages and grades [35].

The biological significance of the coexistence of diploid tumor cells in aneuploid tumors is unknown. Disturbance of the balance between the diploid and aneuploid tumor cell populations, for example in the course of hormonal manipulation, may result in growth advantage of the aneuploid tumor part.

In conclusion, tumor heterogeneity in prostate carcinoma can be found by histopathological evaluation, measurements of DNA ploidy or S-phase fraction in biopsies from various tumor foci or within one tumor biopsy. By increasing the number of biopsies, the probability of detecting the most malignant tumor part increases. However, most effective are simultaneous determinations of tumor grade and DNA ploidy. This is particularly true in the clinical situation in which not all biopsies necessarily contain tumor tissue.

\section{Acknowledgment}

This work was supported by the King Gustaf V Jubilee Foundation.

\section{References}

[1] S. Aaltomaa, M. Eskelinen and P. Lipponen, Expression of cyclin $\mathrm{A}$ and $\mathrm{D}$ proteins in prostate cancer and their relation to clinopathological variables and patient survival, Prostate 38 (1999), 175-182.

[2] S. Aaltomaa, P. Lipponen, S. Vesalainen, M. Ala-Opas, M. Eskelinen and K. Syrjanen, Value of Ki-67 immunolabelling as a prognostic factor in prostate cancer, Eur. Urol. 32 (1997), 410415 . 
[3] M. Aihara, T.M. Wheeler, M. Ohori and P.T. Scardino, Heterogeneity of prostate cancer in radical prostatectomy specimens, Urology 43 (1994), 60-66.

[4] C.L. Amling, S.E. Lerner, S.K. Martin, J.M. Slezak, M.L. Blute and H. Zincke, Deoxyribonucleic acid ploidy and serum prostate specific antigen predict outcome following salvage prostatectomy for radiation refractory prostate cancer, J. Urol. 161 (1999), 857-862.

[5] W. Beyer, Probability and statistics, in: CRC Handbook of Tables for Probability and Statistics, W. Beyer, ed., CRC Press Inc., Boca Raton, FL, 1983, pp. 11-13.

[6] A. Böcking, J. Kiehn and M. Heinzel-Wach, Combined histologic grading of prostatic carcinoma, Cancer 50 (1982), 288294.

[7] M. Borre, S.M. Bentzen, B. Nerstrom and J. Overgaard, Tumor cell proliferation and survival in patients with prostate cancer followed expectantly, J. Urol. 159 (1998), 1609-1614.

[8] D.G. Bostwick, Gleason grading of prostatic needle biopsies. Correlation with grade in 316 matched prostatectomies, Am. J. Surg. Pathol. 18 (1994), 796-803.

[9] W.J. Catalona, A.J. Stein and W.R. Fair, Grading errors in prostatic needle biopsies: relation to the accuracy of tumor grade in predicting pelvic lymph node metastases, J. Urol. 12 (1982), 919-922.

[10] L. Cheng, T.J. Sebo, J. Slezak, T.M. Pisansky, E.J. Bergstralh, R.M. Neumann, K.A. Iczkowski, H. Zincke and D.G. Bostwick, Predictors of survival for prostate carcinoma patients treated with salvage radical prostatectomy after radiation therapy, Cancer 83 (1998), 2164-2171.

[11] E.D. Crawford, D. Hirano, P.N. Werahera, M.S. Lucia, E.P. DeAntoni, F. Daneshgari, P.N. Brawn, V.O. Speights, J.S. Stewart and G.J. Miller, Computer modeling of prostate biopsy: tumor size and location - not clinical significance determine cancer detection, J. Urol. 159 (1998), 1260-1264.

[12] G. Forsslund, B. Nilsson and A. Zetterberg, Near tetraploid prostate carcinoma. Methodologic and prognostic aspects, Cancer 78 (1996), 1748-1755.

[13] J.E. Garnett, R. Oyasu and J.T. Grayhack, The accuracy of diagnostic biopsy specimens in predicting tumor grades by Gleason's classification of radical prostatectomy specimens, J. Urol. 131 (1984), 690-693.

[14] D.F. Gleason, Histologic grading of prostate cancer: a perspective, Hum. Pathol. 23 (1992), 273-279.

[15] D.F. Gleason and G.T. Mellinger, Prediction of prognosis for prostatic adenocarcinoma by combined histological grading and clinical staging, J. Urol. 111 (1974), 58-64.

[16] D.R. Greene, S.R. Taylor, T.M. Wheeler and P.T. Scardino, DNA ploidy by image analysis of individual foci of prostate cancer: a preliminary report, Cancer Res. 51 (1991), 40844089 .

[17] D.J. Grignon and E.H. Hammond, College of American Pathologists Conference XXVI on clinical relevance of prognostic markers in solid tumors. Report of the Prostate Cancer Working Group, Arch. Pathol. Lab. Med. 119 (1995), 1122-1126.

[18] G. Haroske, F. Giroud, A. Reith and A. Bocking, 1997 ESACP consensus report on diagnostic DNA image cytometry. Part I: basic considerations and recommendations for preparation, measurement and interpretation. European Society for Analytical Cellular Pathology, Anal. Cell. Path. 17 (1998), 189-200.
[19] M.E. Harper, L. Goddard, D.W. Wilson, S.S. Matanhelia, I.G. Conn, W.B. Peeling and K. Griffiths, Pathological and clinical associations of Ki-67 defined growth fractions in human prostatic carcinoma, Prostate 21 (1992), 75-84.

[20] T. Heiden, N. Wang and B. Tribukait, An improved Hedley method for preparation of paraffin-embedded tissues for flow cytometric analysis of ploidy and S-phase, Cytometry 12 (1991), 614-621.

[21] K.K. Hodge, J.E. McNeal, M.K. Terris and T.A. Stamey, Random systematic versus directed ultrasound guided transrectal core biopsies of the prostate, J. Urol. 142 (1989), 71-74.

[22] E.C. Jones, J. McNeal, N. Bruchovsky and G. de Jong, DNA content in prostatic adenocarcinoma. A flow cytometry study of the predictive value of aneuploidy for tumor volume, percentage Gleason grade 4 and 5, and lymph node metastases, Cancer 66 (1990), 752-757.

[23] S. Lundberg, J. Carstensen and I. Rundquist, DNA flow cytometry and histopathological grading of paraffin-embedded prostate biopsy specimens in a survival study, Cancer. Res. 47 (1987), 1973-1977.

[24] R.D. Mashal, S. Lester, C. Corless, J.P. Richie, R. Chandra, K.J. Propert and A. Dutta, Expression of cell cycle-regulated proteins in prostate cancer, Cancer Res. 56 (1996), 4159-4163.

[25] S.E. Mills and J.E. Fowler, Jr., Gleason histologic grading of prostatic carcinoma. Correlations between biopsy and prostatectomy specimens, Cancer 57 (1986), 346-349.

[26] G.P. Murphy, C. Busch, P.A. Abrahamsson, J.I. Epstein, J.E. McNeal, G.J. Miller, F.K. Mostofi, R.B. Nagle, S. Nordling, C. Parkinson et al., Histopathology of localized prostate cancer. Consensus Conference on Diagnosis and Prognostic Parameters in Localized Prostate Cancer. Stockholm, Sweden, May 12-13, 1993, Scand. J. Urol. Neph. (Suppl. 162) (1994), $7-42$.

[27] O. Nativ, H.Z. Winkler, Y. Raz, T.M. Therneau, G.M. Farrow, R.P. Myers, H. Zincke and M.M. Lieber, Stage C prostatic adenocarcinoma: flow cytometric nuclear DNA ploidy analysis, Mayo Clin. Proc. 64 (1989), 911-919.

[28] F.P. O’Malley, D.J. Grignon, M. Keeney, N. Kerkvliet and C. McLean, DNA heterogeneity in prostatic adenocarcinoma. A DNA flow cytometric mapping study with whole organ sections of prostate, Cancer 71 (1993), 2797-2802.

[29] D. van den Ouden, B. Tribukait, J.H. Blom, S.D. Fossa, K.H. Kurth, F.J. ten Kate, T. Heiden, N. Wang and F.N. Schroder, Deoxyribonucleic acid ploidy of core biopsies and metastatic lymph nodes of prostate cancer patients: impact on time to progression, J. Urol. 150 (1993), 400-406.

[30] J. Qian, D.G. Bostwick, S. Takahashi, T.J. Borell, J.A. Brown, M.M. Lieber and R.B. Jenkins, Comparison of fluorescence in situ hybridization analysis of isolated nuclei and routine histological sections from paraffin-embedded prostatic adenocarcinoma specimens, Am. J. Pathol. 149 (1996), 1193-1199.

[31] E.T. Ruijter, C.A. van de Kaa, J.A. Schalken, F.M. Debruyne and D.J. Ruiter, Histological grade heterogeneity in multifocal prostate cancer. Biological and clinical implications, J. Pathol. 180 (1996), 295-299.

[32] F.H. Schroder, P. Hermanek, L. Denis, W.R. Fair, M.K. Gospodarowicz and M. Pavone-Macaluso, The TNM classification of prostate cancer, Prostate (Suppl. 4) (1992), 129-138. 
[33] T.V. Shankey, P.S. Rabinovitch, B. Bagwell, K.D. Bauer, R.E. Duque, D.W. Hedley, B.H. Mayall, L. Wheeless and C. Cox, Guidelines for implementation of clinical DNA cytometry. International Society for Analytical Cytology, Cytometry 14 (1993), 472-477.

[34] N. Tinari, C. Natoli, D. Angelucci, R. Tenaglia, B. Fiorentino, P. Di Stefano, C. Amatetti, A. Zezza, M. Nicolai and S. Iacobelli, DNA and S-phase fraction analysis by flow cytometry in prostate cancer. Clinicopathologic implications, Cancer $\mathbf{7 1}$ (1993), 1289-1296.

[35] B. Tribukait, Rapid-flow cytometry of prostatic fine needle aspiration biopsies, in: Prognostic Cytometry and Cytopathology of Prostate Cancer, JP, K, ed., Elsevier Science Publishing, 1989, pp. 236-242.

[36] B. Tribukait, Nuclear deoxyribonucleic acid determination in patients with prostate carcinomas: clinical research and application, Eur. Urol. 23 (1993), 64-76.

[37] S. Vesalainen, S. Nordling, P. Lipponen, M. Talja and K. Syrjanen, Progression and survival in prostatic adenocarcinoma: a comparison of clinical stage, Gleason grade, S-phase fraction and DNA ploidy, Bri. J. Cancer 70 (1994), 309-314.

[38] S.L. Vesalainen, P.K. Lipponen, M.T. Talja, E.M. Alhava and K.J. Syrjanen, Proliferating cell nuclear antigen and p53 expression as prognostic factors in $\mathrm{T} 1-2 \mathrm{M} 0$ prostatic adenocarcinoma, Inter. J. Cancer 58 (1994), 303-308.

[39] T. Visakorpi, Proliferative activity determined by DNA flow cytometry and proliferating cell nuclear antigen (PCNA) im- munohistochemistry as a prognostic factor in prostatic carcinoma, J. Pathol. 168 (1992), 7-13.

[40] T. Visakorpi, O.P. Kallioniemi, A. Heikkinen, T. Koivula and J. Isola, Small subgroup of aggressive, highly proliferative prostatic carcinomas defined by $\mathrm{p} 53$ accumulation, J. Natl. Cancer Inst. 84 (1992), 883-887.

[41] T. Visakorpi, O.P. Kallioniemi, I.Y. Paronen, J.J. Isola, A.I. Heikkinen and T.A. Koivula, Flow cytometric analysis of DNA ploidy and S-phase fraction from prostatic carcinomas: implications for prognosis and response to endocrine therapy, Bri. J. Cancer 64 (1991), 578-582.

[42] N. Wang, Y. Pan, T. Heiden and B. Tribukait, Fluorescence image cytometry for measurement of nuclear DNA content in surgical pathology, Cytometry 22 (1995), 323-329.

[43] M.J. Warzynski, C.E. Soechtig, T.J. Maatman, L.C. Goldsmith, M.A. Grobbel, G.G. Carothers and K.F. Shockley, DNA heterogeneity determined by flow cytometry in prostatic adenocarcinoma - necessitating multiple site analysis, Prostate 27 (1995), 329-335.

[44] H.Z. Winkler, L.M. Rainwater, R.P. Myers, G.M. Farrow, T.M. Therneau, H. Zincke and M.M. Lieber, Stage D1 prostatic adenocarcinoma: significance of nuclear DNA ploidy patterns studied by flow cytometry, Mayo Clin. Proc. 63 (1988), 103112 . 


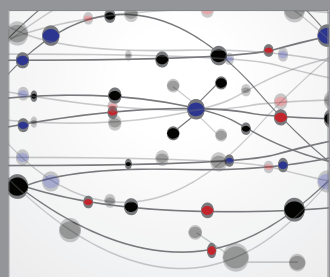

The Scientific World Journal
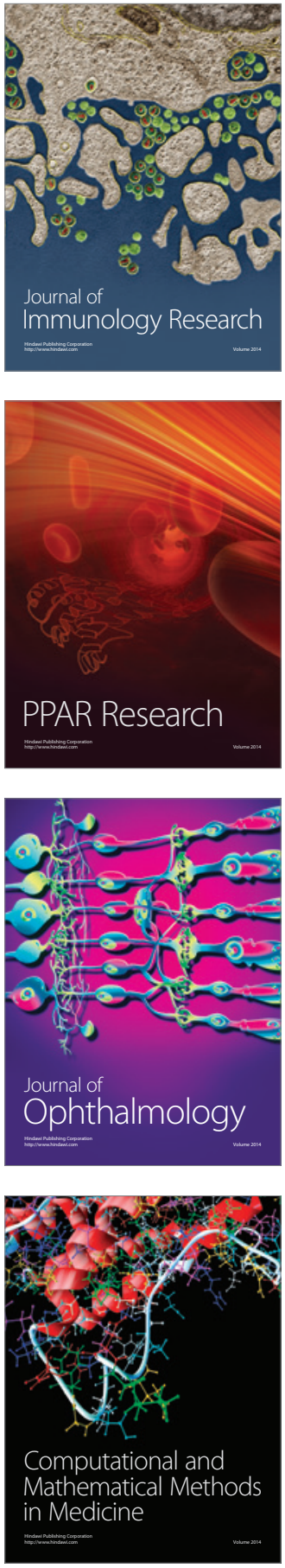

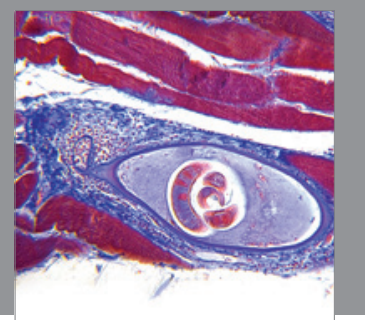

Gastroenterology

Research and Practice
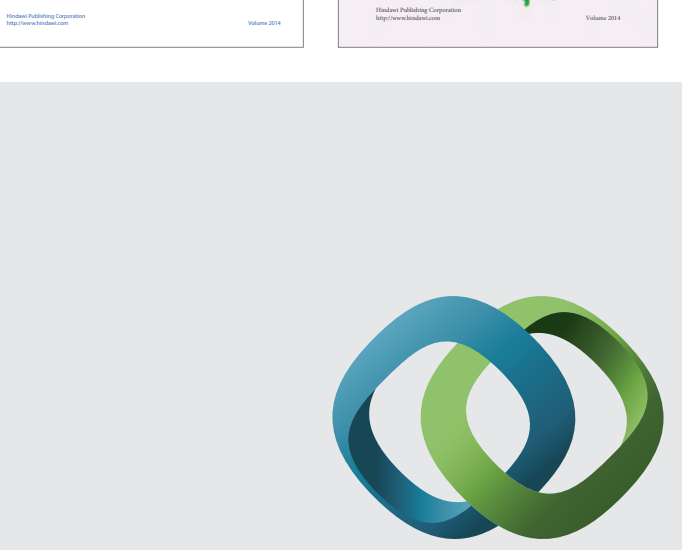

\section{Hindawi}

Submit your manuscripts at

http://www.hindawi.com
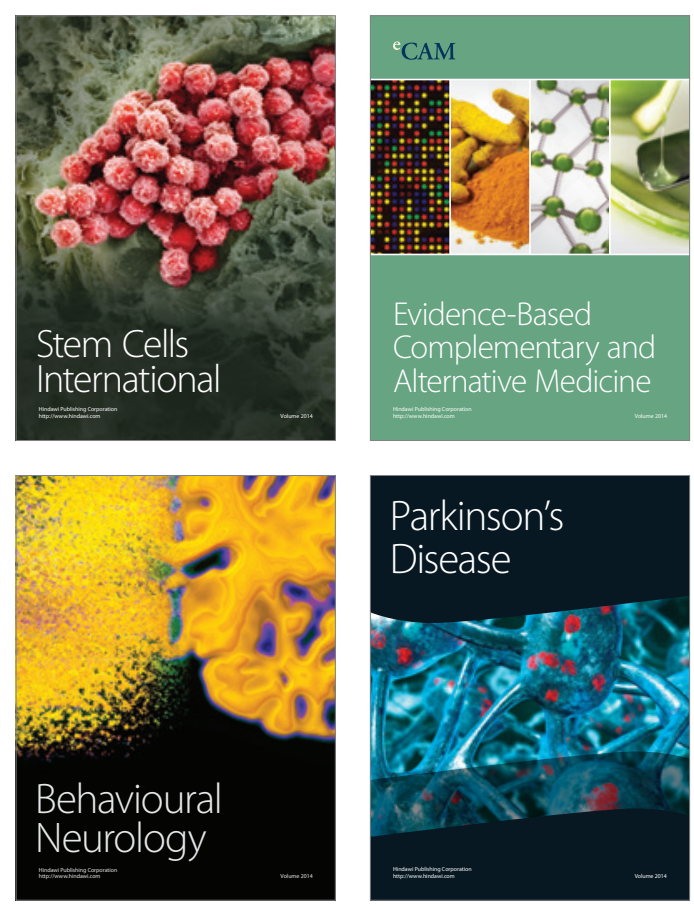

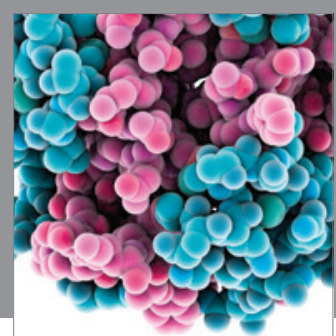

Journal of
Diabetes Research

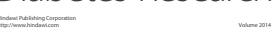

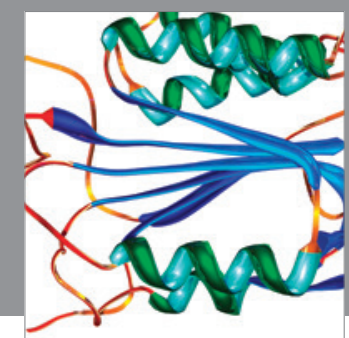

Disease Markers
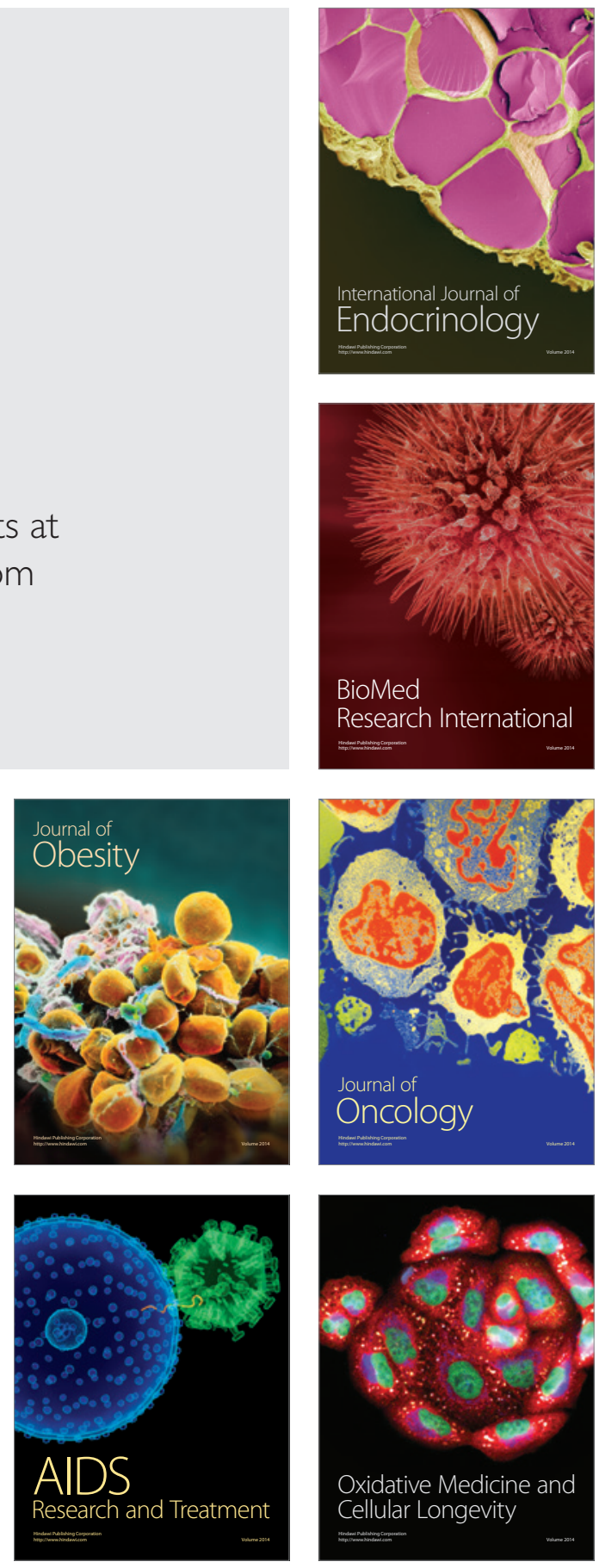